\title{
Rubella-associated arthritis. II. Relationship between circulating immune complex levels and joint manifestations
}

\author{
VIJENDRA K SINGH, ' AUBREY J TINGLE,' AND MICHAEL SCHULZER ${ }^{2}$ \\ From the ${ }^{1}$ Division of Immunology of the Department of Paediatrics, and the ${ }^{2}$ Department of Mathematics, \\ University of British Columbia, Vancouver, British Columbia, Canada
}

SUMMARY The role played by raised circulating immune complex (CIC) levels in the pathogenesis of rubella-associated joint reactions has been assessed during the course of RA 27/3 rubella immunisation and epidemic wild rubella infection. CIC levels were evaluated by $\mathrm{C} 1 \mathrm{q}$ microplate enzyme-linked immunosorbent assay (ELISA) and Raji cell ELISA techniques. Mean CIC levels were generally higher both before and after immunisation among individuals developing vaccine-associated arthritis than among those developing arthralgia or no joint symptoms. However, these differences reached statistical significance only with CIC (Raji) techniques at six and 12 weeks postimmunisation. The proportion of individuals within each group having raised CIC levels ( $\geqslant 2 \mathrm{SD}$ above normal control values) was also higher in the postvaccine arthritis group, though statistically significant differences were not found with either Raji or C1q techniques. These data do not support a direct role for raised CIC levels in the pathogenesis of rubella-associated arthritis or arthralgia.

Key words: rubella, rubella virus, rubella immunisation, immune complexes, pathogenesis.

The pathogenesis of joint manifestations occurring during the course of infection with mild and vaccine strains of rubella virus has remained unclear despite numerous recent studies. ${ }^{1-5} \mathrm{~A}$ possible role for increased levels of circulating immune complexes (CIC) in the development of joint symptoms has been suggested by the temporal association between the onset of joint manifestations and the appearance of circulating rubella-specific antibody. ${ }^{6}$ In addition, the detection of rubella virus persistence in peripheral blood mononuclear cells in patients with prolonged rubella-associated arthritis ${ }^{7}$ provides an opportunity for recurrent rubella virus antigenaemia and subsequent CIC formation. Preliminary experimental support for this hypothesis has been provided by the detection in rubella-associated arthropathy of raised CIC levels by the $\mathrm{Clq}$ binding technique ${ }^{4}$ and increased frequency of rubellaspecific immunoglobulins in CIC isolated from

Accepted for publication 24 July 1985.

Correspondence to Dr Aubrey Tingle. Division of Immunology, Room 2K5. Children's Hospital, 4480 Oak Street. Vancouver. V6H 3V4, BC, Canada. patients developing arthralgias after rubella immunisation. $^{5}$

The present study attempts to evaluate the role played by increased CIC levels in the pathogenesis of joint manifestations at intervals after RA 27/3 rubella immunisation and wild rubella infection.

\section{Patients and methods}

PATIENTS AND CONTROLS

The rubella vaccine study group consisted of 44 adult rubella haemagglutination inhibition seronegative females undergoing routine rubella RA 27/3 immunisation (Meruvax II, Merck Sharp and Dohme) as outlined previously. ${ }^{8}$ Serum samples were obtained before vaccination and one, two, three, four, five, six, 12 , and 24 weeks postvaccine. The wild rubella infection group consisted of 46 individuals ( 23 males, 23 females) presenting with acute rubella infection during an epidemic in an outlying community as reported previously. ${ }^{8}$ Serum samples were obtained randomly from a proportion of individuals with and without joint symptoms during the acute and convalescent postrubella 
infection period. Control groups for the $\mathrm{Clq}$ and Raji immune complex assays consisted of randomly selected normal healthy adult laboratory personnel and hospital staff.

In each study group sera were stored in aliquots at $-70^{\circ} \mathrm{C}$ for no longer than 12 months before use in immune complex assay determinations.

C1q BINDING ASSAY

A Clq microplate ELISA modification of the C1q binding assay was employed as previously described. ${ }^{9}$
R A J I A S S A Y

A microplate ELISA modification of the Raji cell assay was employed as previously described. ${ }^{10}$

STATISTICAL STUDIES

Multiple tests were performed on $\log _{10}$ data compar-o ing CIC levels at intervals in wild and vaccine groups $\overline{\bar{n}}$ with the appropriate control sets. Owing to multiple dependency in the data Bonferroni-type adjustments to significance levels were made. Further ${ }^{\mathrm{s}}$ support for results was obtained by calculating an $\vec{\circ}$ analogous set of non-parametric tests (Wilcoxon-
A Normal No joint symptoms

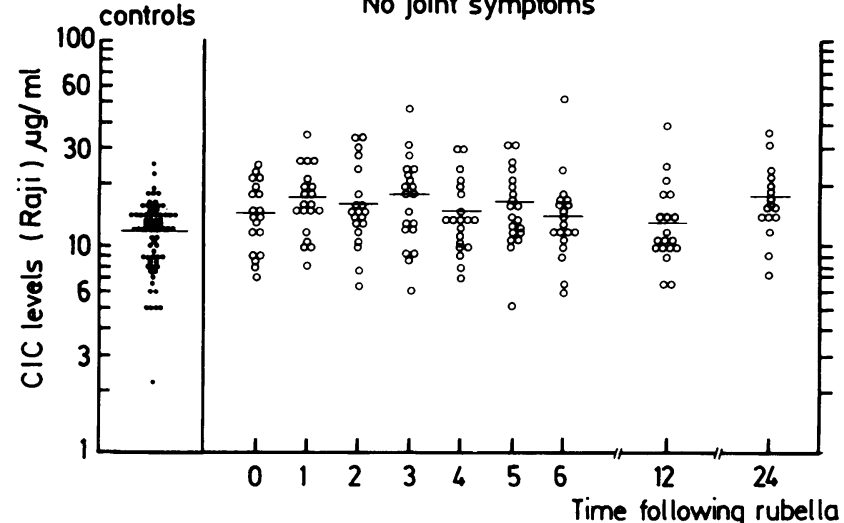

Joint symptoms

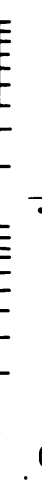

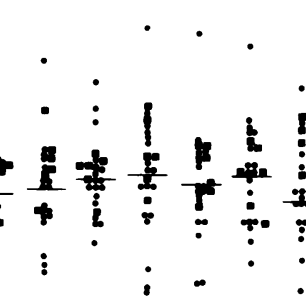


rank sum). In addition, analyses of variance were performed between groups experiencing arthralgia, arthritis, or no joint symptoms postinfection and control groups at each time interval postinfection. These studies were further supported by nonparametric check tests (Kruskal-Wallis).

\section{Results}

RUBELLA VACCINE STUDIES

The temporal relationship between CIC (Raji) levels and the development of joint manifestations after RA 27/3 rubella immunisation is shown in Fig. 1A. The geometric mean of CIC (Raji) levels was observed to be higher in preimmunisation samples obtained from individuals developing vaccineassociated arthritis (mean $=17.98)$ than from those developing arthralgia (mean $=12.95)$ or no joint symptoms $($ mean $=13 \cdot 76)$. Similar findings were also noted at virtually all time periods postimmunisation, though statistically significant differences were only noted between postvaccine arthritis and arthralgia groups at six weeks $(\mathrm{p}<0.01)$ and 12 weeks $(\mathrm{p}<0.01)$ postimmunisation. This was due in part to the high variability observed in individual CIC levels within each group. No statistically significant differences were noted at any follow-up time period when mean CIC (Raji) levels among groups developing arthritis or arthralgia postimmunisation were compared with those in individuals developing no joint symptoms at all in the postvaccine follow-up period.

The proportion of each group developing raised
CIC (Raji) levels ( $\geqslant 2$ SD above the mean value of normal control values) did not differ significantly among postvaccine groups developing arthralgia or arthritis or no joint symptoms (Table 1 ).

When CIC values were evaluated by the $\mathrm{Clq}$ microplate ELISA technique similar findings were observed (Table 1, Fig. 1B). Again, individuals developing acute polyarthritis had higher mean CIC (C1q) levels than those groups experiencing arthralgia or no joint manifestations in the postvaccine follow-up period. No statistically significant differences were noted in either mean CIC (C1q) levels between each patient group and the proportion of each group having raised CIC levels.

\section{WILD RUBELLA INFECTION STUDIES}

In contrast with CIC studies carried out in the rubella vaccine group, a more pronounced rise in CIC (Raji) and CIC (C1q) levels was observed at 0 and two weeks after wild rubella infection (Table 2 , Figs $2 \mathrm{~A}$ and $\mathrm{B}$ ). Higher mean $\mathrm{CIC}$ levels were again observed among individuals developing joint manifestations postinfection than among those remaining asymptomatic during the follow-up period. These differences never reached levels of statistical significance.

\section{Discussion}

The present study does not support a clear relationship between raised circulating immune complex levels and the development of joint manifestations

Table 1 The incidence of raised CIC levels in relation to the development of joint manifestations after RA $27 / 3$ rubella immunisation

\begin{tabular}{|c|c|c|c|c|c|c|c|c|c|c|c|c|c|c|c|}
\hline \multirow{3}{*}{$\begin{array}{l}\text { Time } \\
\text { post- } \\
\text { vaccine } \\
\text { (weeks) }\end{array}$} & \multicolumn{15}{|c|}{ Postvaccine joint manifestations } \\
\hline & \multicolumn{5}{|l|}{ None } & \multicolumn{5}{|c|}{ Arthralgia } & \multicolumn{5}{|l|}{ Arthritis } \\
\hline & $\begin{array}{l}\text { Number } \\
\text { tested }\end{array}$ & \multicolumn{2}{|c|}{$\begin{array}{l}\text { Raji } \\
\text { CIC } \\
\text { positive* }^{*}\end{array}$} & \multicolumn{2}{|c|}{$\begin{array}{l}\text { CIq } \\
\text { CIC } \\
\text { positive }\end{array}$} & $\begin{array}{l}\text { Number } \\
\text { tested }\end{array}$ & \multicolumn{2}{|c|}{$\begin{array}{l}\text { Raji } \\
\text { CIC } \\
\text { positive }\end{array}$} & \multicolumn{2}{|c|}{$\begin{array}{l}\text { Clq } \\
\text { CIC } \\
\text { positive }\end{array}$} & $\begin{array}{l}\text { Number } \\
\text { tested }\end{array}$ & \multicolumn{2}{|c|}{$\begin{array}{l}\text { Raji } \\
\text { CIC } \\
\text { positive }\end{array}$} & \multicolumn{2}{|c|}{$\begin{array}{l}\text { Clq } \\
\text { CIC } \\
\text { positive }\end{array}$} \\
\hline 0 & 20 & 1 & (5) & 1 & $(5)$ & 18 & 1 & $(5 \cdot 6)$ & 0 & $(0)$ & 6 & 1 & $(16 \cdot 7)$ & 0 & $(0)$ \\
\hline 1 & 20 & 4 & (20) & 0 & (0) & 18 & 1 & $(5 \cdot 6)$ & 1 & $(5 \cdot 6)$ & 6 & 1 & $(16 \cdot 7)$ & 0 & (0) \\
\hline 2 & 20 & 4 & (20) & 0 & (0) & 18 & 3 & $(16 \cdot 7)$ & 0 & (0) & 6 & 0 & (0) & 1 & $(16 \cdot 7)$ \\
\hline 3 & 20 & 3 & (15) & 0 & (0) & 18 & 5 & $(27 \cdot 8)$ & 0 & (0) & 6 & 2 & $(33 \cdot 3)$ & 1 & $(16 \cdot 7)$ \\
\hline 4 & 20 & 2 & (10) & 0 & (0) & 18 & 2 & $(11 \cdot 1)$ & 1 & $(5 \cdot 6)$ & 6 & 0 & (0) & 0 & (0) \\
\hline 5 & 20 & 3 & (15) & 0 & (0) & 18 & 5 & $(27 \cdot 8)$ & 0 & (0) & 6 & 1 & $(16 \cdot 7)$ & 0 & (0) \\
\hline 6 & 20 & 1 & (5) & 0 & (0) & 18 & 2 & $(11 \cdot 1)$ & 0 & (0) & 6 & 3 & (50) & 0 & (0) \\
\hline 12 & 20 & 1 & (5) & 0 & (0) & 17 & 1 & $(5.9)$ & 0 & (0) & 6 & 0 & (0) & 1 & $(16 \cdot 7)$ \\
\hline & 16 & 2 & $(12 \cdot 5)$ & 0 & (0) & 14 & 3 & $(21.4)$ & 1 & $(7 \cdot 1)$ & 4 & 0 & (0) & 0 & (0) \\
\hline Overall & 20 & 9 & (45) & 1 & (5) & 18 & 7 & $(38 \cdot 9)$ & 2 & $(11 \cdot 1)$ & 6 & 5 & $(83 \cdot 3)$ & 1 & $(16 \cdot 7)$ \\
\hline
\end{tabular}

${ }^{*}$ CIC level $\geqslant 2 \mathrm{SD}$ above the geometric mean of normal control sera.

†No statistically significant differences were noted in the percentage CIC positive between groups developing arthritis, arthralgia, or no joint manifestations after rubella immunisation. 
A
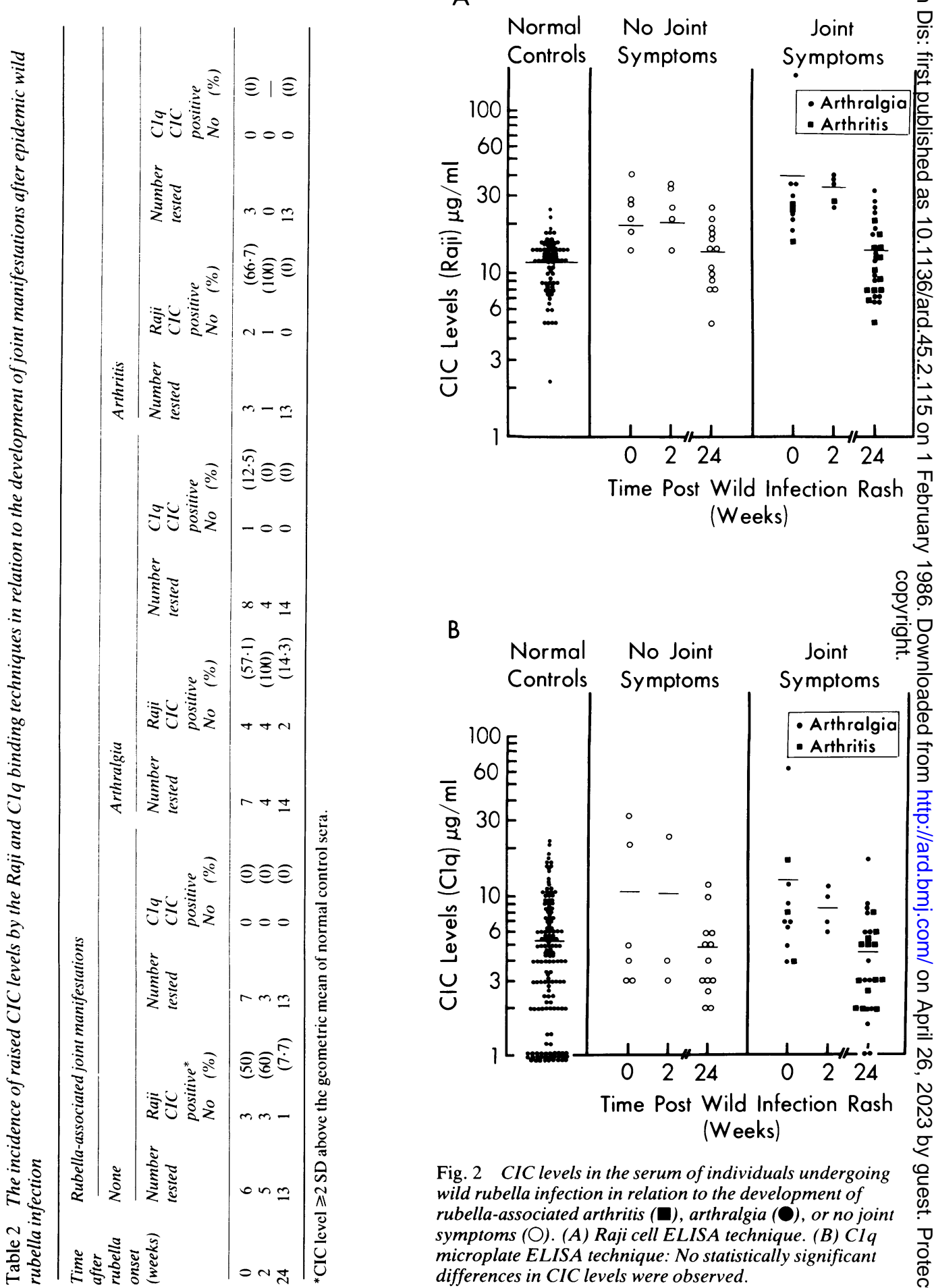

Time Post Wild Infection Rash (Weeks)

B
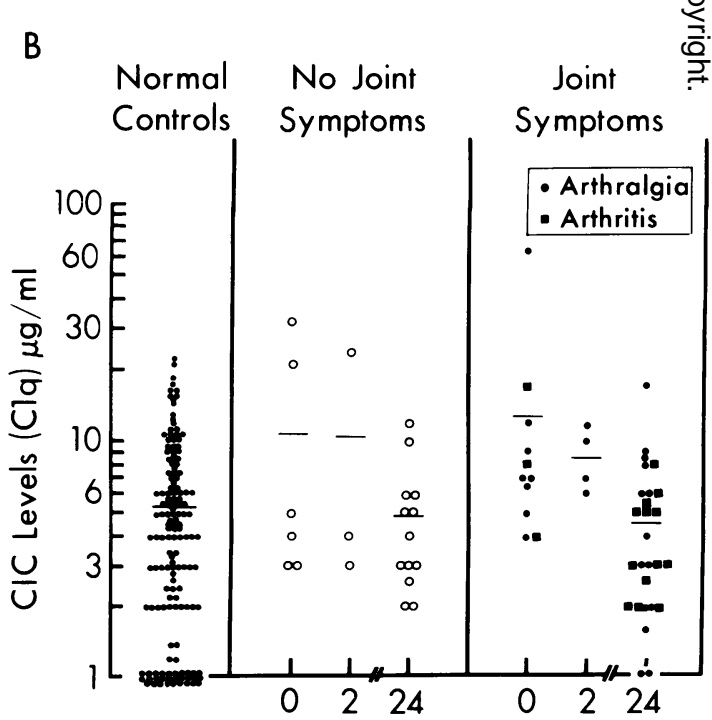

Fig. 2 CIC levels in the serum of individuals undergoing wild rubella infection in relation to the development of rubella-associated arthritis (ם), arthralgia (Q), or no joint symptoms (O). (A) Raji cell ELISA technique. (B) Clq microplate ELISA technique: No statistically significant differences in CIC levels were observed. 
after infection with either vaccine or wild strains of rubella virus. Although CIC levels were higher overall among individuals developing arthritis or arthralgia postinfection, mean values did not differ statistically from those observed in the group developing no joint manifestations postinfection. In addition, the incidence of raised or positive CIC levels did not differ between symptomatic and non-symptomatic groups in both the rubella immunisation and wild rubella infection study populations. In many instances, clearly raised CIC levels were observed postinfection in individuals experiencing no joint symptoms at all. Other individuals who developed marked polyarticular arthritis maintained negative CIC levels throughout the follow-up period. An additional interesting but unexplained observation was that preimmunisation CIC levels were higher by both $\mathrm{C} 1 \mathrm{q}$ binding and Raji techniques in subjects subsequently developing polyarticular arthritis than in individuals developing arthralgias or no joint symptoms postinfection.

Previous studies ${ }^{4}$ had suggested a possible role for raised CIC levels in the pathogenesis of rubellaassociated joint manifestations. Vergani et al. ${ }^{4}$ observed raised CIC levels by the $\mathrm{Clq}$ binding technique in three of three adults developing joint symptoms 10 to 15 days after immunisation with the Cendehill (Almevax) strain of rubella virus and in only one of seven previously rubella antibody negative adults with no vaccine-related joint manifestations. Coyle et al. ${ }^{5}$ observed CIC containing rubella-specific $\mathrm{IgG}$ at prolonged follow-up periods in 11 of 14 individuals developing joint symptoms after either RA $27 / 3$ or HPV-77 DE/5 rubella immunisation. However, the latter investigators also detected rubella-specific CIC in 22 of 38 individuals reporting no joint symptoms at all. It is clear from these studies and our present observations that although increased CIC levels may be observed in individuals developing rubella-associated joint man- ifestations, no clear correlation has been established between the presence of raised CIC levels and the development of arthritis or arthralgia after rubella infection. However, it remains possible that the local formation, deposition, and persistence of rubella-specific immune complexes within synovial fluid or joint tissues may have an important role in the pathogenesis of rubella-associated arthritis.

This work was supported by grants from the Medical Research Council of Canada and the British Columbia Health Care Research Foundation. We thank Linda Kwong for excellent technical assistance and Anne Sinclair for preparation of the manuscript.

\section{References}

1 Chiba Y, Sadeghi E, Ogra P L. Abnormalities of cellular immune responses in arthritis induced by rubella vaccination. $J$ Immunol 1976; 117: 1684-7.

2 Tingle A J, Yang T, Allen M, Kettyls G D, Larke R P B, Schulzer M. Prospective immunological assessment of arthritis induced by rubella vaccine. Infect Immun 1983; 40: 22-8.

3 Ziola B, Lund G, Meurman O, Salmi A. Circulating immune complexes in patients with acute measles and rubella virus infections. Infect Immun 1983; 41: 578-83.

4 Vergani D, Morgan-Capner P, Davies E T, Anderson A W, Tee D E H, Pattison J R. Joint symptoms, immune complexes, and rubella. Lancet 1980; ii: 321-2.

5 Coyle P K, Wolinsky J S, Buimovici-Klein E, Moucha R, Cooper L Z. Rubella-specific immune complexes after congenital infection and vaccination. Infect Immun 1982; 36: 498-503.

6 Cooper L Z, Ziring P R, Weiss H J, Matter B A, Krugman S. Transient arthritis after rubella vaccination. Am J Dis Child 1969; 118: $218-25$.

7 Chantler J K, Ford D K, Tingle A J. Persistent rubella infection and rubella-associated arthritis. Lancet 1982; i: 13235.

8 Tingle A J, Allen M, Petty R E, Kettyls G D, Chantler J K. Rubella-associated arthritis. I. Comparative study of joint manifestations associated with natural rubella infection and RA 27/3 rubella immunisation. Ann Rheum Dis 1986; 45: 110-4.

9 Singh V K, Tingle A J. Detection of circulating immune complexes by a C1q-microplate ELISA system. I Immunol Methods 1982; 50: 109-14.

10 Singh V K, Kwong L C. Quantitation of soluble immune complexes by a microplate Raji cell-ELISA method. Immunol Lett (in press). 